\title{
A Bibliometric Analysis of Branding Trends: Does Irrationality Really Matter?
}

\author{
Jana Majerova ${ }^{1, *}$, Lubica Gajanova $^{1}$, and Margareta Nadanyiova $^{1}$ \\ ${ }^{1}$ University of Zilina, Faculty of Operation and Economics of Transport and Communications, \\ Department of Economics, Slovak Republic
}

\begin{abstract}
Irrationality and its transposition into theory of consumer behaviour is generally considered to be one of the leading trends in contemporary managerial research. It becomes to be notoriety without need of its verification in conditions of specifics of managerial practice across products and markets. However, there are still platforms for discussion about its impact on current state of knowledge. One of these platforms is brand management. On the one hand - the most dominant brand value source is its image creating attribute where irrationality has its undisputable position but on the other hand - qualitative attributes of brand are still considered as significant. Thus, the rationality is highlighted in scope of branding. Therefore, the schism between rationality and irrationality is visible. The aim of this paper is to identify the position of irrationality in the branding trendology. Methodologically, VOSviewer has been used as a basic research platform for the bibliometric analysis of contemporary scientific literature. We have found out, that there is a significant discrepancy between trends in branding theory worldwide and in Slovak Republic. Thus, we create platform to discuss about the applicability of branding patterns which have been modified in scope of irrationality and questioning the existence of Homo Oeconomicus.
\end{abstract}

Keywords: brand, branding, irrationality, bibliometric analysis

\section{Introduction}

Consumption is an integral part of human existence. It can be considered as a driving force for the sustainable development of national economies. As early as 1776, Adam Smith stated that the wealth of nations comes from the production and consumption of goods and services. Consumption has thus become the object of research, not only from an economic but also from a sociological or psychological perspective. This fact is also stated by the fact that the Nobel Prize in Economics was awarded in 2017 to Richard H. Thaler, who researches the psychological factors behind the economic decisions of individuals. By emphasizing the need to take into account the psychological attributes of decision-making of individuals as economic entities, Thaler became one of the key representatives of the school, the so-called behavioural economics, the projection of which into corporate reality across the various areas of its management, becomes an imperative of the effective

*Corresponding author: jana.majerova@fpedas.uniza.sk 
operation of the company in the market aimed at achieving defined strategic goals. While at the macro level the behavioural approach to consumption is a relatively new line of thought, at the micro level the application of behavioural principles is experiencing a renaissance. In the context of corporate governance, there has been a deviation in the recent past from the original emphasis on the need to take them into account in favour of implementing quantitative methods, even in traditionally behavioural areas such as marketing $[1,2,3]$. However, the fundamental divergence of the essence of problem areas of marketing and such methods of solution has ultimately proved that the behavioural approach has the status of condition sine qua non not only in marketing but also in the complex management of the company. On the one hand, consumption, which accelerates business activity and the development of national economies, is the subject of macroeconomic research, on the other hand, it transcends at the micro level through almost all business activities. Since behaviour as such is a cross-cutting sociological-psychological category, its examination in the context of consumption as a purely economic category explicitly requires the application of a behavioural approach. Consumer behaviour is traditionally defined as goal-oriented behaviour in which individuals (consumers), resp. their groupings, acquire, use, hold or dispose of goods and services with the intention of increasing their satisfaction and saturating their living needs while maximizing the usefulness gained [4,5]. The fact that these processes are not always efficient is in favour of rejecting the theory of rationality. According to Wansink, a significant part of the products purchased (more than 12\%) is never used [6].

\section{Theoretical background}

Table 1 summarizes the genesis of the theory of rationality in consumer behaviour.

Table 1. Genesis of the theory of rationality in consumer behaviour

\begin{tabular}{|c|c|l|}
\hline Author & Date & \multicolumn{1}{c|}{ Nature } \\
\hline Smith, A. & 1776 & The first rationally conceived theory of consumption \\
\hline Mill, J.S. & 1836 & $\begin{array}{l}\text { The first recorded simplification of man for the needs of } \\
\text { economics }\end{array}$ \\
\hline Jevons, W.S. & 1865 & $\begin{array}{l}\text { The mechanical concept of economic man, which formed } \\
\text { the basis of neoclassical economics }\end{array}$ \\
\hline Menger, C. & 1871 & $\begin{array}{l}\text { An alternative approach to rationality in economics based on } \\
\text { border conditions and the establishment of a tradition on } \\
\text { which the marginal current of economic thinking close so } \\
\text { far, the so-called classical economics }\end{array}$ \\
\hline Becker, G. & 1992 & $\begin{array}{l}\text { A shift from the simplification of man as an economic } \\
\text { subject to greater complexity while preserving the } \\
\text { mathematical nature of the created models }\end{array}$ \\
\hline
\end{tabular}

Source: Own processing according to Zalega $[7,8]$.

An unambiguous definition of rationality in the consumer behaviour of an individual is still absent in the professional literature. In fact, the only agreement between the authors is that a person behaves rationally if he always chooses the one that is best for him from the variants available to him. This is done by satisfying these basic axioms:

- axiom of comparison complexity - it is necessary for the consumer to be able to decide whether product A brings him higher, lower or equivalent benefit than product B,

- axiom of transitivity - assuming that the benefit of product $\mathrm{A}$ is higher than the benefit of product $\mathrm{B}$ and at the same time the benefit of product $\mathrm{B}$ is higher than 
the benefit of product $\mathrm{C}$, the benefit of product $\mathrm{A}$ is higher than the benefit of product $\mathrm{C}$,

- the axiom of greed - a larger number of products is always considered more beneficial than a smaller amount, provided that the product provides the consumer with a positive satisfaction of his needs,

- the axiom of diversity - the consumer prefers to achieve average consumption over extreme differences in consumption [9].

The fact that these axioms are not fully fulfilled in every consumer decision-making was admitted by neoclassical economists, but did not consider this fact in their models, which is a significant shortcoming [10]. They also disagreed on what is best for the consumer. In this sense, many variants come into consideration - from a very narrow definition, where the criterion is understood own benefit, which can be quantified in monetary units as the highest profit, or the smallest possible loss (absolutely rationalist), to a very broad definition of own benefit., which may include such factors as sincere interest in other people, prestige, evaluation of oneself as a good person, etc. (partially behaviouralistic). However, irrational factors, the existence of which the proponents of the theory of rationality were aware of on the one hand, were considered inexplicable redundancies of economic events, which resulted in the belief that their inclusion in models to improve their predictive abilities is not possible. The theory of irrationality in consumer behaviour is based on the assumption that human behaviour is not sufficiently explainable using the assumptions of rationality and that we can achieve a more accurate result only if we assume some systematic lack of rationality in the model. The basic stream of ideas based on the denial of rationality in consumer behaviour is the school of so-called behavioural economics, which is elaborated in the professional literature by several theories. These vary among themselves due to changes in assumptions and in the approach to modifying standard (usually neoclassical) models. These theories are: 1) theory of limited rationality; 2) prospect theory; 3 ) theory of mental accounting and 4) theory of selfcontrol.

The theory of limited rationality originated in 1957, when H. Simon first defined the term "limited rationality" as a means of proposing a rational choice that takes into account the cognitive limits of the economic entity - the decision-maker, i.e. limits arising from his knowledge and subjective possibilities. This theory is based on the assumption that the decision maker selects from the given alternatives with a known probability distribution the result that maximizes the expected value of a given utility function. What is best for the consumer is based on his subjective judgment.

The theory of prospects, formulated by D. Kahneman and A. Tversky in 1979, is an alternative theory to the theory of limited rationality. Its essence lies in the fact that it is a natural aversion to loss for the consumer, as a result of which the probability of unlikely events is overestimated and the probability of normally probable events is underestimated. The aversion to loss is always assessed against a certain reference point, which in practice means that the same situation can be assessed differently by consumers. A specific feature of this theory is that it does not assume the consumer's orientation according to the resulting usefulness, but according to the subjectively perceived value. The difference between these approaches is that while the utility function displays the benefit of various possible states, the value function describes the relationship between individual changes and their subjectively perceived value [11].

The theory of mental accounting was developed by Thaler in 1985 to explain irrationality in consumers' financial decisions. In principle, it is based on the value function characteristic of the theory of prospects and begins to work with the concept of hedonic efficiency, which defines the consumer's effort to ensure that the transactions he considers bring him maximum satisfaction with minimal psychological harm. It assumes that the 
revenues and losses of the implemented decision are evaluated with respect to a subjectively perceived reference point, which is derived from the nature of the sources of financing and the approach to the perception of the risk of the transaction. The basis of this theory is therefore the analysis of subjectivism in the perception and evaluation of realized transactions, in the division of sources of their financing into the so-called mental accounts and in the periodicity of evaluating the efficiency of management on individual accounts [12].

The theory of self-control is based on the assumption of the existence of a discrepancy between the intended and actual actions. It assumes that current consumption has a higher added value for the consumer than deferred consumption. This implies the need to reconsider the exponential discount approach to quantify future consumption benefits. Instead of an approach based on discounting equally large periods of time at the same discount rates, a modified approach is needed, where periods closer to the present need to be discounted at higher discount rates. The phenomenon manifests itself in the fact that if the consumer plans a future purchase, his plans may change at the moment the future merges with the present, without any other change in circumstances [13]. Solomon states that, in addition to traditional psychological categories, irrationality in consumer behaviour is also influenced by categories resulting from other social sciences [14]. This theory identifies micro and macro-consumer behaviour; giving it a predominantly psychological (micro) and sociological (macro) dimension. The theory follows from the concept of individual freedom of decision and the degree of influence of endogenous, resp. exogenous factors on his shopping behaviour. However, the current literature rejects such an approach and returns to emphasizing the behavioural nature of the phenomenon of consumer behaviour explored through the prism of its dualistically conceived psychologicalsociological aspects in the context of consumption as a key economic variable $[15,16]$. This approach modifies the traditional concept of shopping behaviour formulated in the context of the so-called triads of purchasing situations (ordinary or repeated purchase, modified purchase and new purchase) with respect to the degree of rational consumer involvement (cognitive, habitual and affective shopping behaviour). This concept follows the models of consumer behaviour formulated by Blackwell-Miniard-Engel [17]. Although these models state the presence of sociological and psychological influences, they abstract from their concretization across products and markets, thus actually evaluating the significance of these aspects in the context of neoclassical postulates and thus do not reflect the scientific shift from rationalism to behaviouralism. Unlike models constructed in other areas of economic research, which have a strong predictive power, for this reason, the models of consumer behaviour constructed so far have a persistent descriptive character and mostly serve as a support apparatus for ex post analysis. The above also applies to brand management models, which were paradoxically built on behavioural pillars when they were created. There are several reasons why the behavioural-oriented approach is currently experiencing a renaissance within them. In the context of corporate governance, the most important of these are:

- short-term trend of transition from behaviouralism to the implementation of the principles of so-called marketing engineering and emphasis on quantitative methods,

- the need to revise the originally conceived models with regard to regional disparities of behavioural aspects of brand management.

In the context of theoretical concepts of brand management with a significant immediate impact on corporate governance, it is the fragmentation of theoretical approaches leading to the decline of the strategic dimension of brand management at the corporate level. The implementation of fragmented theoretical approaches to the behavioural aspects of brand management leads to an undesirable spiral effect. It has the following course: domestic 
companies apply inappropriate concepts of brand management - brand value does not grow further or decreases - managers prefer to abandon the strategic dimension of brand management activities - domestic brands lose their competitive potential compared to foreign - the market is distorted - remain in the market only strong foreign brands using their original management concepts - the impression of the so-called "good practice" domestic brand managers apply seemingly effective foreign concepts and the cycle repeats itself.

\section{Methodology}

The idea of visualizing bibliometric networks, often referred to as science mapping, has received serious attention since the early days of bibliometric research. Visualization has turned out to be a powerful approach to analyze a large variety of bibliometric networks, ranging from networks of citation relations between publications or journals to networks of co-authorship relations between researchers or networks of co-occurrence relations between keywords. Over time, researchers have started to analyze larger and larger networks, leading to the need for more advanced visualization techniques and tools. At the same time, professional users of bibliometrics, for instance research institutions, funding agencies, and publishers, have become more and more interested in bibliometric network visualizations. To make bibliometric network visualizations available to a wider public, both inside and outside the bibliometric research community, researchers have developed a number of software tools, most of which are freely available. Nowadays, widely used are these two: VOSviewer and CitNetExplorer. VOSviewer is a tool that we have developed over the past few years and that offers in a relatively easy way the basic functionality needed for visualizing bibliometric networks $[18,19]$. The VOSviewer provides distance-based visualizations of bibliometric networks. By default, VOSviewer therefore displays only the nodes in a bibliometric network and does not display the edges between the nodes. In the visualizations provided by VOSviewer, the distance between two nodes approximately indicates the relatedness of the nodes. By providing distance-based visualizations rather than graph-based ones, VOSviewer is especially suitable for visualizing larger networks. Because of its strong focus on visualization, VOSviewer offers less functionality for analyzing bibliometric networks than other tools. However, VOSviewer does have some special text mining features. We've applied VOSviewer on the data obtained in Web of Science database since year 2016 to be sure that only hot topics are included to detect trends in scope of brand value building and management. We didn't focus only on top journals in this field, but we've applied key words approach regardless source of the paper. Thus, brand management has been investigated while to criteria to the inclusion of the topic obtaining this key words has been its appearance in more than twelve sources. Based on this, clustering could be provided. The basic dataset has been formed by more than 3000 papers.

\section{Results}

The aim of the paper was to identify the position of irrationality in the branding trendology. Methodologically, VOSviewer has been used as a basic research platform for the bibliometric analysis of contemporary scientific literature. We have found out, that there is a significant discrepancy between trends in branding theory worldwide and in Slovak Republic. The reason for studying the trends in brand value building and management separately worldwide and in Slovak Republic was that in specific conditions of Slovak Republic, quality is still perceived as main brand value source while in 
worldwide perspective, image is dominating brand value source. Thus, it has been at the beginning of the research expected that irrationality and behaviourism would be relevant to trendology worldwide where image is perceived as main brand value source. Similarly, in scope of Slovak Republic, irrationality wouldn't be perceived as leading trend in branding due to the fact that quality is traditionally considered as main brand value source.

As it is shown in Fig. 1 where the spheres of interest of scientific community in scope of brand management worldwide are graphically expressed, the irrationality resp. behaviourism is not detected as individual area of interest. It is included in "green group" considered as brand attributes where significant attention is paid to behavioural loyalty. However, it is obvious that irrationality is indirectly included in all the created groups of interest of contemporary branding science. These groups are: 1) retail branding (red); 2) digital branding (blue); 3) brand attributes (green); 4) brand value sources (yellow) and 5) regional specifics of branding (violet).

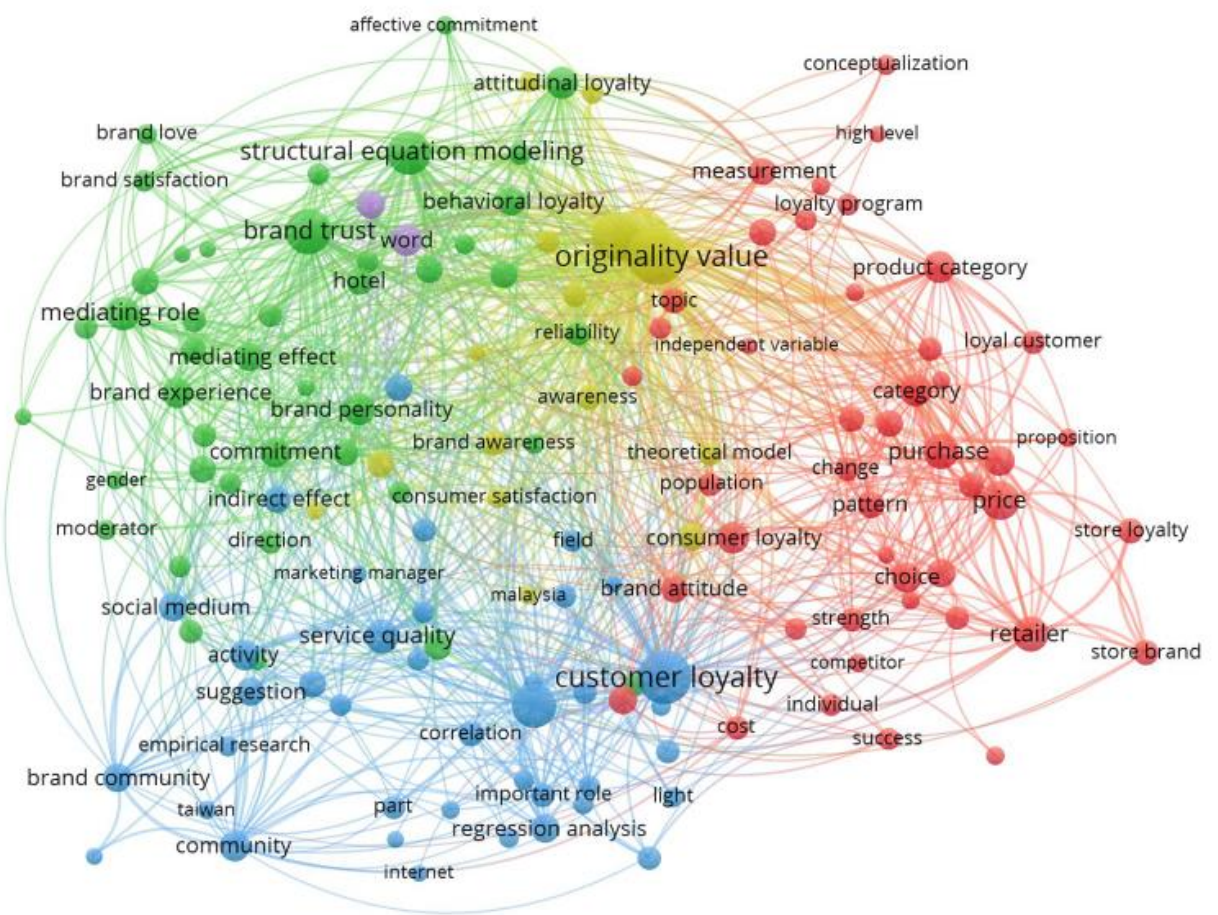

Fig. 1. Spheres of interest of scientific community in scope of brand management worldwide Source: Own processing in VOSviewer platform.

As it is shown in Fig. 2 where the spheres of interest of scientific community in scope of brand management in Slovak Republic are graphically expressed, the irrationality resp. behaviourism is not detected as individual area of interest. When comparing the bibliometric map and identified areas of interest of contemporary branding science worldwide and in Slovak Republic, the explicit appearance of attribute "behavioural" is not present in specific conditions of Slovak Republic. It can be also stated, that irrationality is neither indirectly included in the created groups of interest of contemporary branding science. These groups are: 1) consumer perception (red); 2) Slovak specifics of branding (green) and 3) financial aspects of branding (blue). Thus, the original presumption that irrationality and behaviourism is relevant to trendology worldwide where image is perceived as main brand value source, has been partially verified. Similarly, in scope of 
Slovak Republic, it has been proven that irrationality is not perceived as leading trend in branding due to the fact that quality is traditionally considered as main brand value source.

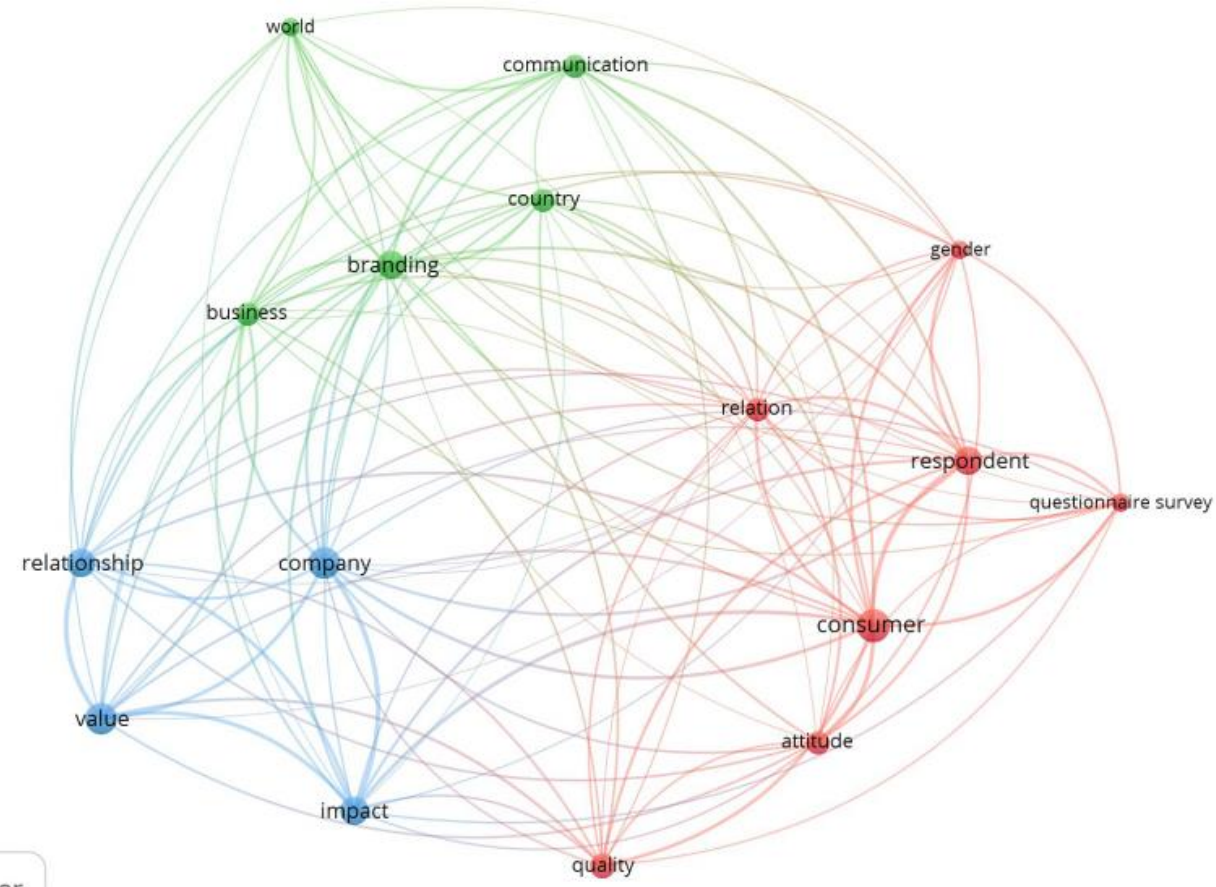

ewer

Fig. 2. Spheres of interest of scientific community in scope of brand management in Slovak Republic Source: Own processing in VOSviewer platform.

\section{Conclusion}

The aim of the paper was to identify the position of irrationality in the branding trendology. We've assumed that there will be significant difference between importance of irrationality in branding worldwide and in specific conditions of Slovak Republic. The reason for such a presumption was that the irrationality and behaviourism would be relevant to trendology where image is perceived as main brand value source (worldwide) while it wouldn't be perceived as leading trend in branding due to the fact that quality is traditionally considered as main brand value source (Slovak Republic). Methodologically, VOSviewer has been used as a basic research platform for the bibliometric analysis of contemporary scientific literature. We have found out that branding trends worldwide are: 1) retail branding; 2) digital branding; 3) brand attributes; 4) brand value sources and 5) regional specifics of branding. In specific conditions of Slovak Republic these trends are: 1) consumer perception; 2) Slovak specifics of branding and 3) financial aspects of branding. Thus, we have verified the original assumption about significant difference in branding trendology based on the dominant brand value source (image generally vs. quality in Slovak Republic). This fact indicates the need of systematic evaluation of trends in contemporary brand management provided in the light and shadow of bibliometric overview.

This contribution is an output of scientific project VEGA no. 1/0718/18: The impact of psychographic aspects of pricing on the marketing strategy of companies across products and markets. 


\section{References}

1. S. Parihar, Actors Affecting Consumer Involvement in Purchase of Garments: A Quantitative Analysis for Marketing Strategies. The Journal of Indian Management \& Strategy, 22(2), pp. 24-31 (2017)

2. M.E. David, F.R. David, F.R. David, The Quantitative Strategic Planning Matrix: A New Marketing Tool. Journal of Strategic Marketing, 25(4), pp. 342-352 (2017)

3. P. Ceniga, V. Sukalova, Future of logistics management in the process of globalization. Procedia Economics and Finance, 26, 160-166 (2015)

4. M. Kienzler, C. Kowalkowski, Pricing Strategy: A Review of 22 Years of Marketing Research. Journal of Business Research, 78, pp. 101-110 (2017)

5. K. Matusinska, M. Stoklasa, The state of strategic marketing application in Czech small and medium-sized enterprises. Scientific Annals of Economics and Business, 66(2), 193-212 (2019)

6. B. Wansink, A. Brasel, S. Amjad, The Mystery of the Cabinet Castaway: Why We Buy Products We Never Use. Journal of Family and Consumer Sciences, 92(1), pp. 104107 (2000)

7. T. Zalega, Rationality and Methods of Research into Consumer Market Behaviour. Equilibrium-Quarterly Journal of Economics and Economic Policy, 7(4), pp. 77-99 (2012)

8. J. Olah, E. Krisan, A. Kiss, Z. Lakner, J. Popp, PRISMA statement for reporting literature searches in systematic reviews of the bioethanol sector. Energies, 13(9), 2323 (2020)

9. G. Barros, H. A. Simon, The Concept of Rationality: Boundaries and Procedures. Revista de Economia Política, 30(3), pp. 455-472 (2010)

10. M. Klepek, The role of demographic factors in consumer perception of value from brand communication on Facebook. Central European Business Review, 9(3), 56-73 (2020)

11. D. Kahneman, A. Tversky, Prospect Theory: An Analysis of Decision Under Risk. Econometrica: Journal of the Econometric Society, 47(2), pp. 263-291 (1979)

12. R.H. Thaler, Mental Accounting and Consumer Choice. Marketing Science, 4(3), pp. 199-214 (1985)

13. R.H. Thaler, Behavioral Economics. Journal of Political Economy, 125(6), pp. 17991805 (2017)

14. M.R. Solomon, Consumer Behaviour: Buying, Having and Being. Essex: Pearson (2015)

15. H. Willman-Iivarinen, The Future of Consumer Decision Making. European Journal of Futures Research, 5(1), 14 (2017)

16. E. Giampietri et al., A Theory of Planned Behaviour Perspective for Investigating the Role of Trust in Consumer Purchasing Decision Related to Short Food Supply Chains. Food Quality and Preference, 64, pp. 160-166 (2018)

17. R.D. Blackwell, P.W. Miniard, J.F. Engel, Consumer Behaviour. 9th edition. Mason, Ohio: South-Western College Publishing (2001)

18. T. Chankoson, T. Thabhiranrak, The moderating role of brand awareness between the relationship of emotional attachment, brand relationship and positive word of mouth. Polish Journal of Management Studies, 20(1), 129-138 (2019) 
19. L. Lizbetinova, The quality of communication in the context of regional development. DETUROPE-The Central European Journal of Regional Development and Tourism, 6(3), 22-38 (2014) 